\title{
Effect of electron beam irradiation on the structure and optical properties of nickel oxide nanocubes
}

\author{
P A SHEENA ${ }^{1}$, K P PRIYANKA ${ }^{2}$, N ALOYSIUS SABU ${ }^{2}$, S GANESH $^{3}$ and THOMAS VARGHESE,* \\ ${ }^{1}$ M.E.S. Asmabi College, P. Vemballur 680 671, Kerala, India \\ ${ }^{2}$ Nanoscience Research Centre (NSRC), Department of Physics, Nirmala College, Muvattupuzha 686 661, Kerala, India \\ ${ }^{3}$ Microtron Centre, Mangalore University, Mangalagangotri 574 199, Karnataka, India
}

MS received 5 September 2014; accepted 30 March 2015

\begin{abstract}
This work reports the effect of electron beam (EB) irradiation on the structure and optical properties of nanocrystalline nickel oxide $(\mathrm{NiO})$ cubes. $\mathrm{NiO}$ nanocubes were synthesized by the chemical precipitation method. The characterization was carried out by employing analytical techniques like X-ray diffraction, transmission electron microscopy, UV-visible and photoluminescence (PL) spectroscopy. The present investigation found that nonstoichiometry, defects and particle size variation caused by EB irradiation have a great influence on optical band gap, blue shift and band modification of absorption and PL spectra. Moreover, EB irradiation can result enhanced optical absorption performance and photo-activity in $\mathrm{NiO}$ nanocubes for optoelectronics and photo-catalytic applications. The study of International Commission on Illumination chromaticity diagram indicates that NiO can be developed as a suitable phosphor material for the application in near ultraviolet excited colour LEDs.
\end{abstract}

Keywords. Nickel oxide; chemical precipitation; electron beam irradiation; band gap.

\section{Introduction}

Nanoparticles of transition metal oxides have been investigated by several workers in the last few years. Out of these, nickel oxide $(\mathrm{NiO})$ nanoparticles, as an important metal oxide with a wide band gap act as a P-type semiconductor, ${ }^{1}$ draw much attention due to its broad range of high-technology application. NiO shows interesting optical, electrical and magnetic properties. Magnetic measurement showed that the $\mathrm{NiO}$ nanoparticles exhibit superparamagnetic behaviour at $300 \mathrm{~K}^{2}$ It is a promising candidate for wide range of applications such as gas sensors, ${ }^{3}$ catalysts ${ }^{4-6}$ anode material in $\mathrm{Li}$ ion batteries, ${ }^{7,8}$ nanoscale optoelectronic devices such as electrochromic display ${ }^{9}$ and so on.

Various techniques have been adopted for the synthesis of $\mathrm{NiO}$ nanostructures such as sol-gel, ${ }^{10,11}$ co-precipitation, ${ }^{12}$ hydrothermal, ${ }^{13}$ solvo-thermal ${ }^{14}$ and chemical precipitation. ${ }^{15}$

In the present study, $\mathrm{NiO}$ nanocubes have been synthesized using the chemical precipitation route, which is simple and low cost. The as-prepared and electron beam (EB) irradiated $\mathrm{NiO}$ samples are characterized by X-ray diffraction (XRD), transmission electron microscopy (TEM), UV-visible spectroscopy and photoluminescence (PL) spectroscopy. In addition, dose-dependent effect of $8 \mathrm{MeV}$ EB irradiation on the structural parameters and optical properties of nanocrystalline $\mathrm{NiO}$ powder samples is also investigated.

\footnotetext{
*Author for correspondence (nanoncm@gmail.com)
}

\section{Experimental}

Nickel nitrate hexahydrate $\left(\mathrm{Ni}\left(\mathrm{NO}_{3}\right)_{2} \cdot 6 \mathrm{H}_{2} \mathrm{O}, 99.8 \%\right.$, Merck) and ammonium carbonate $\left(\left(\mathrm{NH}_{4}\right)_{2} \mathrm{CO}_{3}, 99.9 \%\right.$, Merck) were used without further purification for the synthesis of $\mathrm{NiO}$. Distilled water was used in all synthesis procedures.

\subsection{Preparation of sample}

Synthesis procedures for preparation of $\mathrm{NiO}$ nanoparticles used in this work were described elsewhere. ${ }^{16}$ Nanocrystalline $\mathrm{NiO}$ samples were prepared by reacting aqueous solutions of nickel nitrate hexahydrate and ammonium carbonate $\left(0.1 \mathrm{M}\right.$ each) by heating at $70^{\circ} \mathrm{C}$ for $2 \mathrm{~h}$ under constant stirring. The green precipitate formed was washed with distilled water several times to remove the unreacted salts. The resultant solution was refluxed at $70^{\circ} \mathrm{C}$ for $20 \mathrm{~h}$ to obtain $\mathrm{NiO}$ nanopowders. The obtained powder samples were calcined in a muffle furnace at $400^{\circ} \mathrm{C}$ for $2 \mathrm{~h}$, which resulted in a black solid mass. The flow chart showing the scheme of preparation of $\mathrm{NiO}$ nanopowder is shown in figure 1 .

The $\mathrm{NiO}$ samples were taken in microtubes and subjected to EB irradiation at a distance of $30 \mathrm{~cm}$ from the beam exit port. The samples were irradiated at a dose rate of 2, 4 and $6 \mathrm{kGy}$ with an $\mathrm{EB}$ of energy $8 \mathrm{MeV}$ obtained from a variable energy Microtron at Mangalore University, Karnataka, India. $\mathrm{S} 1$ is pure sample of $\mathrm{NiO}, \mathrm{S} 2, \mathrm{~S} 3$ and $\mathrm{S} 4$ are irradiated samples with dose rates of 2, 4 and $6 \mathrm{kGy}$, respectively.

\subsection{Characterization techniques}

The thermogravimetric (TG) analysis of the precursor was carried out using a Perkin Elmer, diamond instrument with 


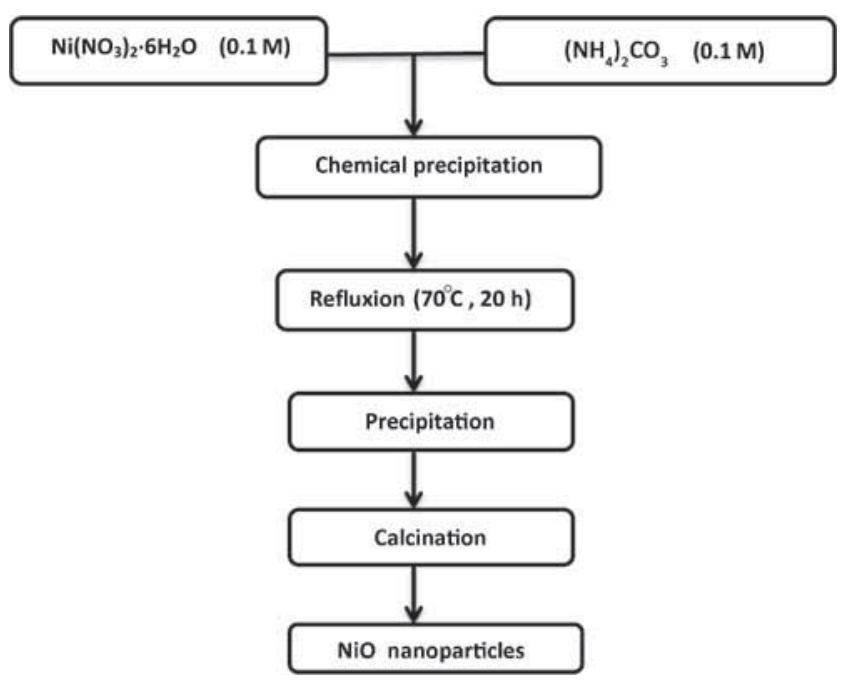

Figure 1. Scheme of preparation of $\mathrm{NiO}$ nanocubes.

a heating rate of $10.00^{\circ} \mathrm{C} \mathrm{min}^{-1}$. The structural characteristics of pure and irradiated $\mathrm{NiO}$ samples were studied by $\mathrm{X}$-ray powder diffraction using Bruker D8 Advance X-ray diffractometer $\left(\lambda=1.5406 \AA\right.$, step size $=0.020^{\circ}$ and dwell time $=31.2 \mathrm{~s}$ ) with $\mathrm{CuK} \alpha$ radiation in $2 \theta$ range from $20^{\circ}$ to $80^{\circ}$. TEM and HRTEM images of the pure sample annealed at $400^{\circ} \mathrm{C}$ were recorded on a JEOI-2010 at an accelerating voltage of $200 \mathrm{kV}$.

Shimadzu 2600/2700 UV-visible spectrophotometer was used to record the optical absorption spectra of the pure and irradiated $\mathrm{NiO}$ nanocube samples in a wavelength range of 200-600 nm. PL spectra of the pure and EB irradiated samples of $\mathrm{NiO}$ were measured at room temperature by a Fluoromax 3 spectrophotometer.

\section{Results and discussion}

\subsection{TG analysis of the precursor}

Selection of suitable calcination temperature is based on the results of TG analysis. Figure 2 shows the thermal decomposition result of the precursor from the ambient temperature to $700^{\circ} \mathrm{C}$ with both the TG and the differential thermogravimetric (DTG) curves. The TG curve indicated that the weight loss of the precursor occurred from 50 to $350^{\circ} \mathrm{C}$. This suggests that the precursor decomposed completely around $350^{\circ} \mathrm{C}$ to become $\mathrm{NiO} .^{7,17}$

Two distinct intervals of weight loss were observed in the TG curve, accompanied by two peaks of weight loss rate in the DTG curve. The first peak located around $100^{\circ} \mathrm{C}$ might be attributed to the thermal dehydration of the precursor and the evaporation of physically adsorbed impurities. The second peak near $300^{\circ} \mathrm{C}$ may be related to the decomposition of nickel carbonate. Based on the results of TGA, a temperature of $400^{\circ} \mathrm{C}$ was chosen to ensure the complete decomposition of the precursor to form $\mathrm{NiO}$.

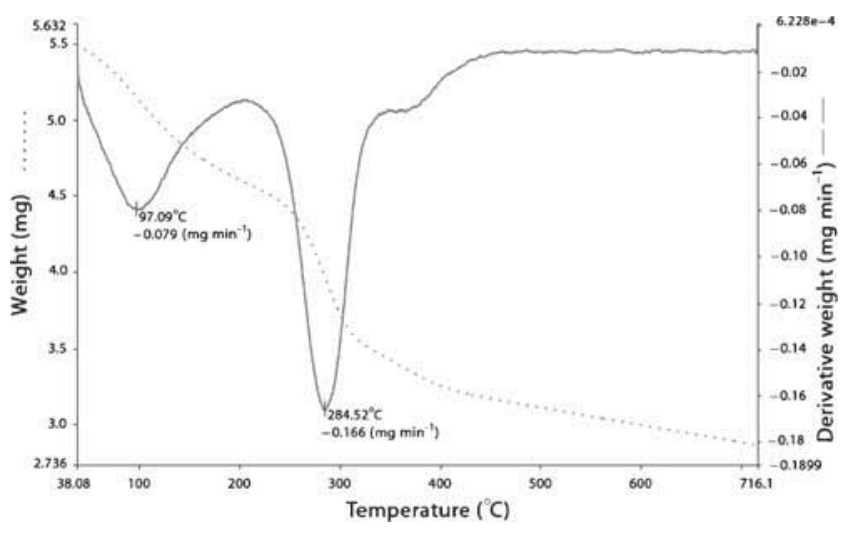

Figure 2. TG/DTG curve for $\mathrm{NiO}$ nanocubes.

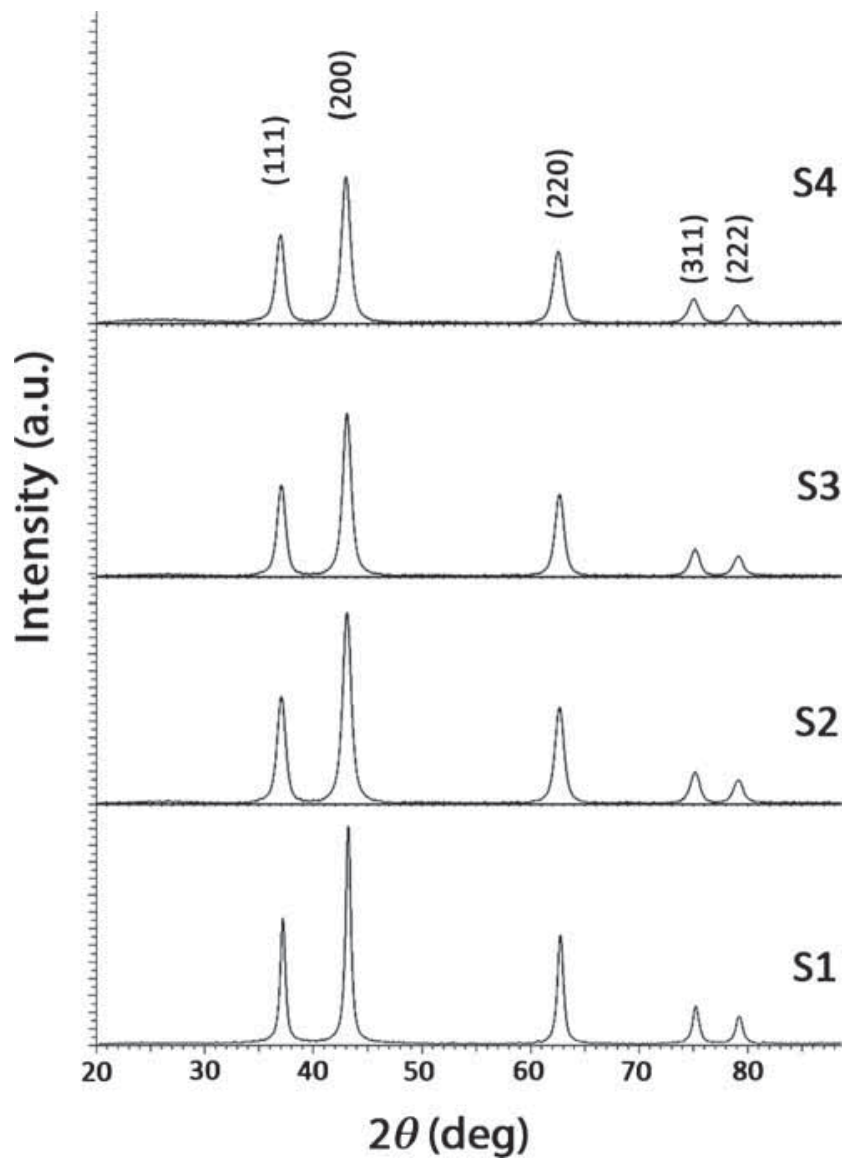

Figure 3. XRD spectra of pure and $\mathrm{EB}$ irradiated $\mathrm{NiO}$ nanocubes.

\subsection{XRD analysis}

The phase composition, purity and structure of the samples were examined using XRD. Figure 3 shows the powder XRD patterns of pure and $\mathrm{EB}$ irradiated samples of $\mathrm{NiO}$ nanoparticles. Well-defined diffraction peaks are observed in the figure corresponding to (111), (200), (220), (311) and (222) planes of cubic $\mathrm{NiO}$ crystals which are in accordance with the standard spectrum (JCPDS, no. 73-1519). ${ }^{11}$ The lattice constant 
of $\mathrm{NiO}$ nanocubes calculated from XRD data is $0.417 \mathrm{~nm}$ which is in good agreement with the reported data. ${ }^{10}$

The crystallite size of all the samples were calculated from the line broadening of the diffraction peaks using Scherrer's formula

$$
D=k \lambda / \beta \cos \theta,
$$

where $D$ represents the average crystallite size, $k=0.89$ (Scherrer constant), $\lambda=1.5406^{\circ}$ (wavelength of the X-ray$\mathrm{Cu} \mathrm{K} \alpha$ radiation), $\theta$ the diffraction angle of the peak and $\beta$ represents the full-width at half-maximum (FWHM) of the peaks. The results are presented in table 1 . Average crystallite sizes obtained for samples S1, S2, S3 and S4 are 15.4, 9.9, 9.4 and $9.1 \mathrm{~nm}$, respectively. The average crystallite size of sample S2 was decreased from 15.4 to $9.9 \mathrm{~nm}$ due to EB irradiation with a dose rate of $2 \mathrm{kGy}$. For S3, the size was decreased to $9.4 \mathrm{~nm}$ after a dose of $4 \mathrm{kGy}$ irradiation, while for $\mathrm{S} 4$, the size was reduced to $9.1 \mathrm{~nm}$ due to an $\mathrm{EB}$ irradiation of $6 \mathrm{kGy}$.

The XRD results show that crystallite size and crystallinity decreased after irradiation. It confirms amorphization of the sample due to irradiation, ${ }^{18}$ which leads for the change in structural and optical properties. The results also show that average particle size decreases with the EB irradiation dose and suggest the possible control of size and density of the $\mathrm{NiO}$ nanoparticles by EB irradiation.

Williamson-Hall analysis ${ }^{19}$ was carried out to calculate the contributions of size and microstrain $\varepsilon$ to XRD line broadening. According to Williamson-Hall model, both small crystallite size and microstrain contribute to the XRD line broadening. This leads to the relation

$$
\beta \cos \theta=k \lambda / D+4 \varepsilon \sin \theta,
$$

The rms microstrain, $\langle\varepsilon\rangle$ is obtained from the slope of the straight line graph obtained by plotting $(\beta \cos \theta) v s$. $(4 \sin \theta)$, while the average crystallite size corrected for microstrain is obtained from the $y$-intercept. The average particle size and microstrain are also presented in table 1 . Very small microstrain values for all the samples lead to the close agreement between the crystallite sizes estimated from Scherrer's equation and Williamson-Hall analysis. It is interesting to note that microstrain values of the samples increases as EB irradiation dose rate is increased. The presence of $\mathrm{O}$ vacancies, structural imperfections and surface defects in $\mathrm{NiO}$ nanoparticle samples due to EB irradiation may cause

Table 1. Geometric parameters of $\mathrm{NiO}$ nanocube samples.

\begin{tabular}{lccc}
\hline & & \multicolumn{2}{c}{ W-H method } \\
\cline { 3 - 4 } Sample & $\begin{array}{c}\text { Particle size }(\mathrm{nm}) \\
\text { Sherrer's equation }\end{array}$ & $\begin{array}{c}\text { Particle size } \\
(\mathrm{nm})\end{array}$ & $\begin{array}{c}\text { Microstrain } \\
\left(* 10^{-3}\right)\end{array}$ \\
\hline S1 & 15.4 & 15.93 & 0.655 \\
S2 & 9.9 & 9.7 & 1.1 \\
S3 & 9.5 & 9.5 & 2.14 \\
S4 & 9.1 & 9.43 & 3.5 \\
\hline
\end{tabular}

increase in microstrain, ${ }^{20,21}$ which in turn result broadening of XRD peaks as shown in figure 3 .

\subsection{TEM analysis}

In order to reveal morphology and size of the synthesized products, typical TEM and HRTEM images have been recorded, as shown in figure 4 . Figure $4 \mathrm{a}$ and $\mathrm{b}$ shows the TEM bright-field images of $\mathrm{NiO}$ nanoparticles calcined at $400^{\circ} \mathrm{C}$. It can be clearly observed that the synthesized product consisted of nearly cube-shaped particles with a size around $15 \mathrm{~nm}$. The average crystallite sizes obtained from Scherrer's formula and W-H analysis are in good agreement with that of TEM images. The lattice fringes can be clearly seen from the HRTEM image (figure 4c), in which interplanar distance is determined to be about $0.21 \mathrm{~nm}$, which is consistent with the $d$ spacing of (200) of cubic NiO. From HRTEM image the unidirectional fringe patterns are clearly observed, which indicates single crystalline nature of $\mathrm{NiO}$ nanoparticle. Selected area electron diffraction pattern (SAED) originated from the $\mathrm{NiO}$ nanoparticle is shown in figure $4 \mathrm{~d}$.

\section{$3.4 U$-vis studies}

Figure 5 shows the UV-visible absorbance spectra of pure and irradiated samples of $\mathrm{NiO}$ nanocubes. It can be seen that there is an exponential decrease in the intensity of absorption with increase in wavelength. This behaviour is typical for many semiconductors and can occur due to various reasons like internal electric fields within the crystal, deformation of lattice due to strain caused by imperfection and inelastic
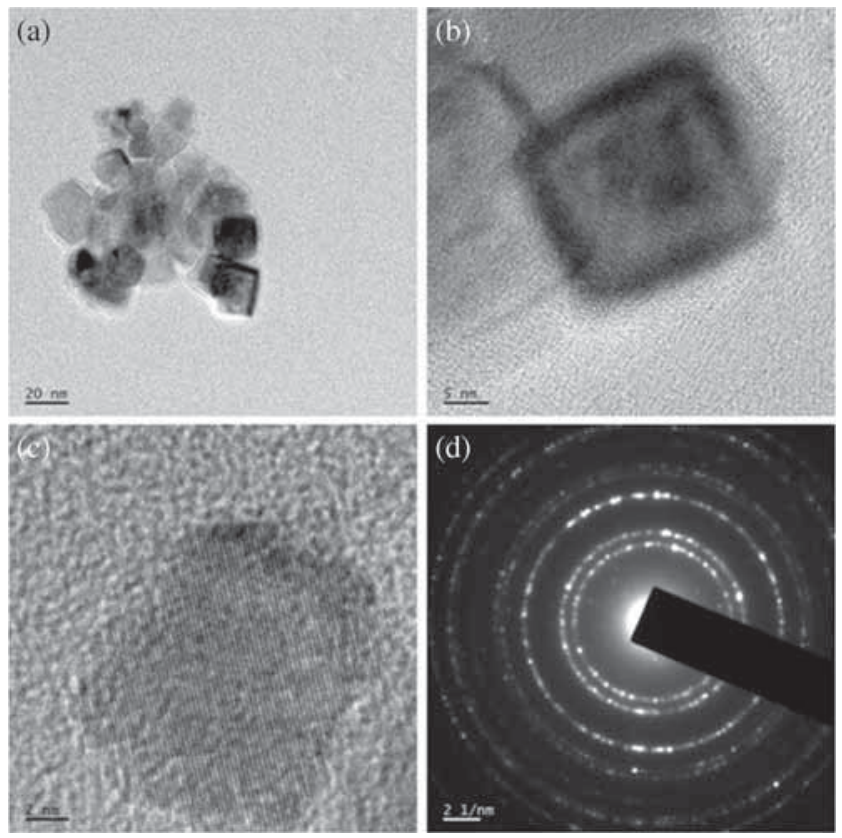

Figure 4. TEM images of $\mathrm{NiO}$ nanocubes calcined at $400^{\circ} \mathrm{C}$. 


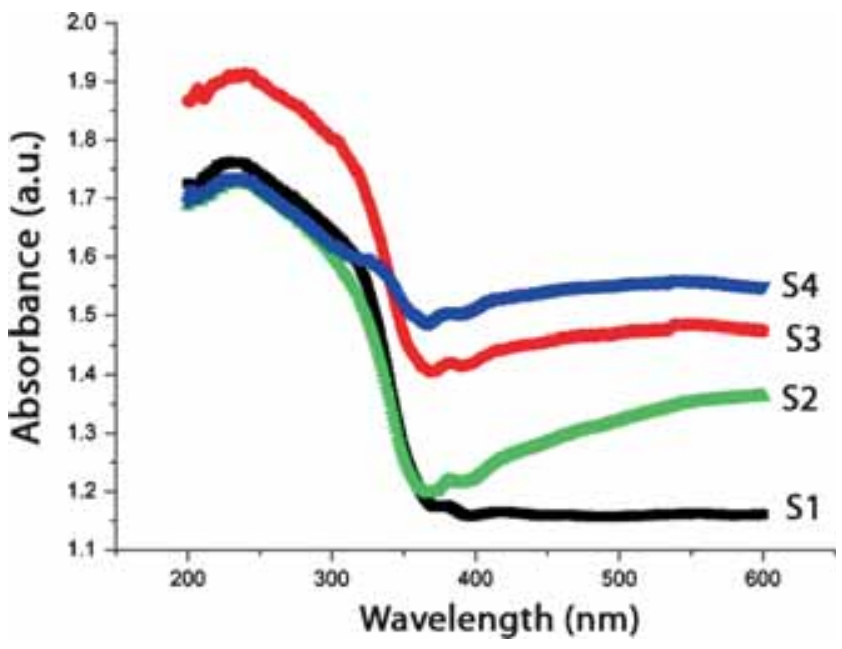

Figure 5. UV-Visible absorption spectra of $\mathrm{NiO}$ nanocube samples.

scattering of charge carriers by phonons. ${ }^{10}$ From the results, it can be observed that the absorption peak of samples S2, S3 and S4 slightly shifts towards the shorter wave length region. This blue shift in the absorption peak is attributed to size reduction of the nanocubes resulting from EB irradiation.

Direct band gap $\left(E_{\mathrm{g}}\right)$ values are determined by fitting absorption data to direct transition equation

$$
\alpha h v=E_{\mathrm{d}}\left(h v-E_{\mathrm{g}}\right)^{1 / 2},
$$

where $\alpha$ is the optical absorption coefficient, $h v$ the photon energy, $E_{\mathrm{g}}$ the direct band gap and $E_{\mathrm{d}}$ the constant. Band gap of $\mathrm{NiO}$ nanocube samples have been measured by plotting $(\alpha h v)^{2}$ as a function of photon energy and extrapolating linear portion of the curve to absorption equal to zero. Optical band gap energy values obtained are 3.26, 3.38, 3.394 and $3.4 \mathrm{eV}$, respectively, for the samples S1, S2, S3 and S4. The optical band gap of $\mathrm{NiO}$ in the present study is lower than the bulk value $(3.65 \mathrm{eV})$. This may be due to the chemical defects or vacancies present in the crystal generating new energy levels to reduce the band gap energy. It is seen that the band gap of $\mathrm{NiO}$ nanocubes shifted from 3.38 to $3.4 \mathrm{eV}$ as particle size reduced from 15.4 to $9.1 \mathrm{~nm}$ due to EB irradiation. This increase in the band gap might occur due to surface band bending with size reduction of the nanoparticles resulting from EB irradiation. ${ }^{22}$ The size reduction causes large surface area to volume ratio, which in turn helps timely utilization of photo-generated carriers in interfacial processes. ${ }^{23}$ Moreover, EB irradiation is a useful technique to enhance the optical absorption performance of $\mathrm{NiO}$ nanocubes.

\subsection{PL studies}

Room-temperature PL emission spectra of pure and irradiated samples of $\mathrm{NiO}$ nanocubes are shown in figure $6 . \mathrm{NiO}$ nanoparticles exhibit a strong and wide peak in the range 2.3$3.4 \mathrm{eV}$ for all the samples with the excited wavelength of $280 \mathrm{~nm}(4.43 \mathrm{eV})$. Samples S1, S2, S3 and S4 show broad

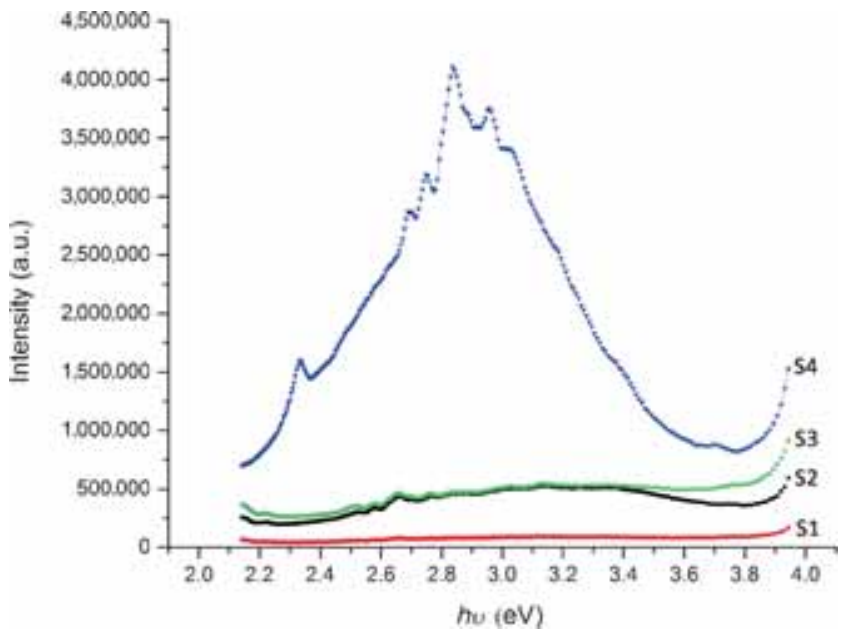

Figure 6. Room temperature PL spectra of $\mathrm{NiO}$ nanocube samples.

PL band centred at about 2.70, 2.72, 2.73 and $2.77 \mathrm{eV}$, respectively, which are smaller than the corresponding optical band gaps. This small blue shit for PL spectra of the EB irradiated samples could be due to surface band bending with surface structural modifications. ${ }^{22}$ The figure (sample S4) also shows some shoulder emission peaks at 3.35, 3.26, $3.13,3.03,2.66,2.58,2.53$ and $2.31 \mathrm{eV}$. The broad peak in PL spectra corresponds to the direct recombination between electrons in the conduction band and holes in the valence band.

The origin of PL peaks attributed to electronic transitions involving $3 \mathrm{~d}^{8}$ electrons of the $\mathrm{Ni}^{2+}$ ions. ${ }^{24,25}$ The visible emission might occur due to the defects related deep-level emission such as oxygen vacancies and Ni interstitials. ${ }^{26}$

The PL spectra of irradiated samples have larger intensities relative to pure sample, due to defects and particle size variation caused by EB irradiation. ${ }^{27}$ Also, the PL intensity increases with dose rate, and the sample S4 irradiated with 6 kGy dose exhibits much larger intensity compared with other samples due to increased absorption over the UV and visible range. Intermediate energy levels are formed with favourable characteristics due to EB irradiation, which are necessary for recombination process (electron/hole) for the improvement of the PL emission at room temperature. ${ }^{18}$ Initially, some electrons from lower intermediate energy levels (oxygen-2p levels) near the valence band absorb the photon energy $(h v)$ at this wavelength $(\lambda=280 \mathrm{~nm})$ and these energetic electrons are promoted to higher intermediate energy levels ( $\mathrm{Ni}-3 \mathrm{~d}$ levels) located near the conduction band. ${ }^{25}$ The energies generated during deexcitation process are converted to photons $\left(h v^{1}\right)$. Several photons originating from the participation of different energy states during the electronic transitions are responsible for the intense PL emission. The increase in PL intensity indicates higher photocatalytic activity of irradiated samples. ${ }^{28}$ There was a small blue shift and broadening for PL spectra of the EB irradiated samples S2, S3 and S4 (figure 6). This blue shift and broadening of PL spectra with size reduction could also be due to 
Table 2. CIE chromaticity coordinates of $\mathrm{NiO}$ nanocube samples.

\begin{tabular}{llc}
\hline & \multicolumn{2}{c}{ CIE coordinates } \\
\cline { 2 - 3 } Sample & \multicolumn{1}{c}{$x$} & \multicolumn{1}{c}{$y$} \\
\hline S1 & 0.199420635 & 0.265229704 \\
S2 & 0.212217088 & 0.295755782 \\
S3 & 0.211600841 & 0.296967316 \\
S4 & 0.17210395 & 0.220446929 \\
\hline
\end{tabular}

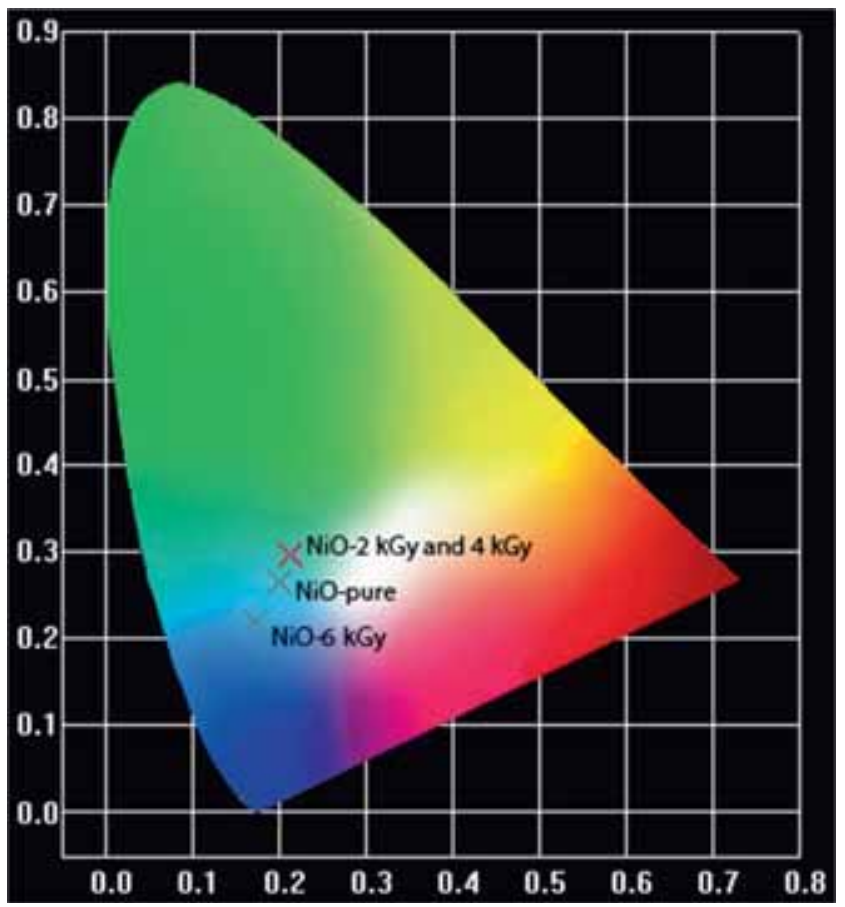

Figure 7. CIE chromaticity diagram of $\mathrm{NiO}$ samples.

surface band bending with surface structural modifications and lattice expansion. ${ }^{22}$

The structural characterization and optical studies of $\mathrm{NiO}$ nanocubes confirm size reduction and structural modifications due to the EB irradiation, which in turn produce blue shift, improved and broadened absorption and PL spectra. Furthermore, EB irradiation is a suitable technique to enhance photo-efficiency and photo-activity of $\mathrm{NiO}$ nanoparticles for varied optoelectronics and photocatalysis applications.

The International Commission on Illumination (abbreviated CIE) $X Y Z$ colour space comprised all colour sensations that an average person can experience. It serves as a standard reference against which many other colour spaces are defined. The chromaticity of a colour is specified by parameters $x$ and $y$, which are projective coordinates and the colours of the chromaticity diagram occupy a region of the real projective plane. The $x$ and $y$ chromaticity coordinates for samples S1, S2, S3 and S4 under the excitation of $280 \mathrm{~nm}$ are calculated in CIE XYZ colour space, and they are presented in table 2. Figure 7 exhibits the CIE chromaticity diagram of pure and irradiated $\mathrm{NiO}$ samples. The bluish-green emission is obtained with CIE coordinates $(0.199420635,0.265229$ $704),(0.212217088,0.295755782)$ and $(0.211600841,0.296$ 967316) for samples S1, S2 and S3, respectively, as shown in figure 7. However, sample S4 exhibits greenish-blue light emission with CIE coordinates of $(0.17210395,0.22044$ 6929). It can be found that by changing the EB irradiation dose rate, the chromaticity coordinates can be tuned from one colour to another. Moreover, the present study suggests that the EB irradiation technique can be used to construct $\mathrm{NiO}$ phosphor for efficient near ultraviolet (NUV) light excited light-emitting diodes (LEDs).

\section{Conclusion}

$\mathrm{NiO}$ nanocubes have been successfully synthesized through the chemical precipitation technique. The effect of $8 \mathrm{MeV}$ EB on their structural and optical properties was studied in order to improve the optical absorption performance and photocatalysis. The size variation, non-stoichiometry and defects of the samples caused by the EB irradiation produced an increase in optical band gap and PL intensity. Moreover, the systematic investigations found that high-energy EB irradiation of suitable dose rate is an efficient technique to promote the optical response and photoactivity of $\mathrm{NiO}$ nanocubes for optoelectronics and photocatalytic applications. The emission hue of the $\mathrm{NiO}$ phosphor can be tuned from one colour to other by changing the $\mathrm{EB}$ irradiation dose rate. Thus, $\mathrm{NiO}$ can be developed as a suitable phosphor material for the application in NUV excited colour LEDs.

\section{Acknowledgements}

We thank to Nirmala College, Muvattupuzha, Kerala, Newman College, Thodupuzha, Kerala and Microtron centre, Mangalore University, Karnataka State, for providing the opportunity to undertake this study. We are grateful to KSCSTE, Thiruvananthapuram, for the financial support. Financial support by UGC (minor project) is gratefully acknowledged by Sheena P A.

\section{References}

1. Palombari R 2003 J. Electroanal. Chem. $\mathbf{5 4 6} 23$

2. Alagiri M, Ponnusamy S and Muthamizhchelvam C $2012 \mathrm{~J}$. Mater. Sci.: Mater. Electron. 23728

3. Matsumiya M, Qiu F, Shin W, Izu N, Murayama N and Kanzaki S 2002 Thin Solid Films $\mathbf{4 1 9} 213$

4. Wang Y, Zhu J, Yang X, Lu L and Wang X 2005 Thermochim. Acta 437106

5. Ichiyanagi $\mathrm{Y}$, Wakabayashi $\mathrm{N}$, Yamazaki J, Yamada S, Kimishima Y, Komatsu E and Tajima H 2003 Physica B 329-333 862

6. Biju V and Abdul Khadar M 2001 Mater. Sci. Eng. A 304-306 814 
7. Li F, Chen H, Wang C and Hu K 2002 J. Electroanal. Chem. $\mathbf{5 3 1} 53$

8. Nuli Y, Zhao S and Qin Q 2003 J. Power Sources 114113

9. Wang G, Zhang L and Mou J 1997 Acta Physico-Chim. Sinica 13445

10. Mallick P, Sahoo C S and Mishra N C 2012 AIP Conf. Proc. 1461229

11. Jeevanandam P and Ranga Rao Pulimi V 2012 Indian J. Chem. 51A 586

12. Mallick P, Chandanarath Biswal R and Mishra N C 2009 Indian J. Phys. 83517

13. Takami S, Hayakawa R, Wakayama Y and Chikyow T 2010 Nanotechnology 21134009

14. Anandan K and Rajendran V 2011 Mater. Sci. Semicond. Process. 1443

15. Chakrabarty S and Chatterjee K 2008 J. Phys. Sci. 13245

16. Sheena P A, Priyanka K P, Aloysius Sabu N, Sabu B and Varghese T 2014 Nanosystems: Phys. Chem. Math. 5441

17. Li J, Yan R, Xiao B, Liang D T and Lee D H 2008 Am. Chem. Soc. 2216
18. Priyanka K P, Aloysius Sabu N, Sunny A T, Sheena P A and Varghese T 2013 J. Nanotechnol. 580308

19. Mote V D, Purushotham Y and Dole B N 2012 J. Theor. Appl. Phys. 61

20. Fernández G M, Martínez-Arias A, Hanson J C and Rodríguez J A 2004 Chem. Rev. 1044063

21. Lorschen C, Brombley S T, Neyman K M and Illas F $2007 \mathrm{~J}$. Phys. Chem. C 11110142

22. Tong W, Li L, Hu W, Yan T, Guan X and Li G 2010 J. Phys. Chem. C 11415298

23. Mo C M, Zhang L and Wang G 1995 Nanostruct. Mater. 6 823

24. Adler D and Feinleib J 1970 Phys. Rev. B 23112

25. Anandan K and Rajendran V 2012 Nanosci. Nanotechnol. Int. J. 224

26. Shah M A 2008 Nanoscale Res. Lett. 3255

27. Gupta S K, Desai R, Jha P K, Sahoo S and Kirin D $2010 \mathrm{~J}$. Raman Spectrosc. 41350

28. Priyanka K P, Aloysious S N, Sheena P A, Sreeja S and Varghese T 2014 Adv. Sci. Eng. Med. 6257 